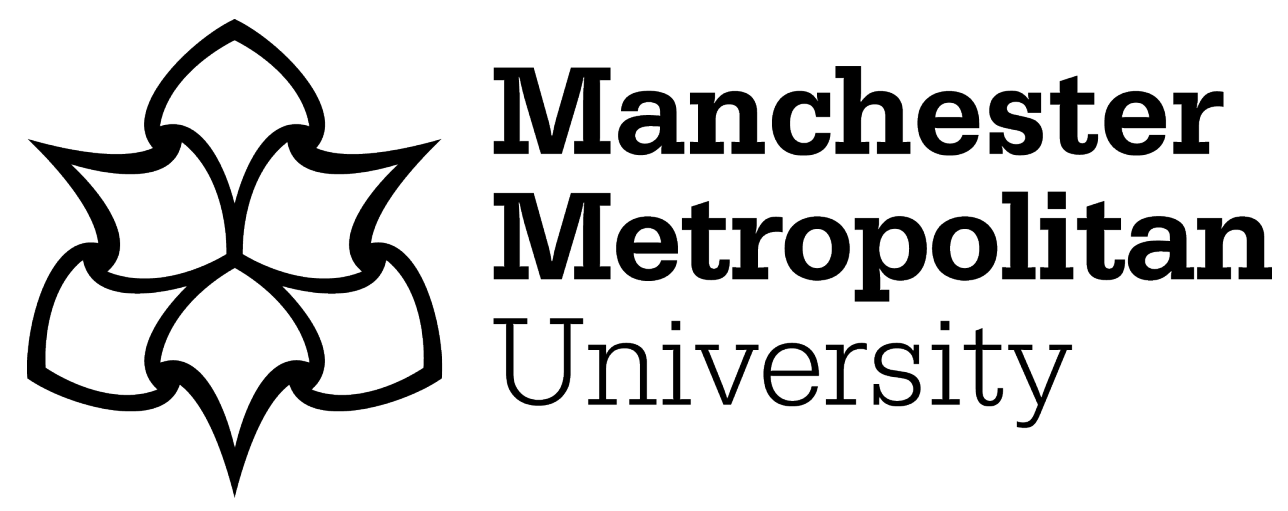

Chadwick, Darren, Chapman, Melanie and Davies, Gill (2018) Factors affecting access to daily oral and dental care among adults with intellectual disabilities. Journal of Applied Research in Intellectual Disabilities, 31 (3). pp. 379-394. ISSN 1360-2322

Downloaded from: https://e-space.mmu.ac.uk/622859/

Version: Accepted Version

Publisher: Wiley

DOI: https://doi.org/10.1111/jar.12415

Please cite the published version 


\title{
Factors affecting access to daily oral and dental care among adults with intellectual disabilities
}

\author{
Darren Chadwick ${ }^{1}$ Corresponding author), Melanie Chapman² \& Gill Davies ${ }^{3}$ \\ ${ }^{1}$ The University of Wolverhampton, Faculty of Education, Health and Wellbeing, \\ University of Wolverhampton, Mary Seacole Building, City Campus - North, Wolverhampton, UK. \\ WV11AD. Tel: 00441902323534. Email:d.chadwick@wlv.ac.uk \\ ${ }^{2}$ Manchester Learning Disability Partnership, Central Manchester University Hospitals NHS \\ Foundation Trust \\ ${ }^{3}$ Greater Manchester Centre and Dental Public Health Intelligence Team, Public Health England
}

\begin{abstract}
Purpose: Accessing oral health care can be more difficult for adults with intellectual disabilities with reports of poorer levels of oral health. This investigation identifies factors influencing engagement in day-to-day oral and dental healthcare for adults with intellectual disabilities.

Method: A survey, containing questions about facilitators and barriers to maintaining oral health and hygiene, was completed with adults with intellectual disabilities and their caregivers $(\mathrm{N}=372)$.

Results: Data were analysed using thematic network analysis. Two global themes were identified; 'Personal and lifestyle influences', mentioned more often as barriers to oral care, included physical, sensory, cognitive, behavioural and affective factors and 'Social and environmental factors', mentioned more as facilitators, included caregiver support, equipment and adaptations used and oral hygiene routine.

Conclusions: Numerous individual, social and environmental factors influence oral care. A coordinated organisational response is advocated involving collaboration between dental and ID services and training for caregivers and people with intellectual disabilities.
\end{abstract}




\section{BACKGROUND}

Oral health refers to the health status of the oral and related tissues and includes dental health. Good oral health enables an individual to eat, speak and interact without embarrassment, discomfort or disease, contributing to an individual's positive wellbeing (British Society of Disability and Oral Health, 2012; Department of Health, 2007). People with intellectual disabilities (ID) face a range of health inequalities, including oral health (Emerson et al., 2012), however, there is a lack of research identifying factors that impede or facilitate access to daily oral care for people with ID.

The impact of oral and dental conditions on an individual's health and quality of life can be profound (Manley et al., 2000). Good oral health has been implicated in improvements in communication and nutrition and has been linked with improved self-esteem and confidence, dignity, social integration and quality of life (Barr et al., 1999; Fiske et al., 2000; Department of Health, 2007). Conversely, poorer oral health has been connected with detrimental effects such as problems with eating, pain and discomfort, which people with ID may find difficult to communicate (Gallagher and Scambler, 2012; Department of Health, 2007; Turner et al., 2012). Oral diseases have complex interrelationships with many systemic diseases commonly seen in aging individuals with ID. Chronic oral infections, usually in the form of periodontitis (gum disease), have been associated with cardiovascular disease, cerebrovascular disease, poorly controlled diabetes and other systemic disorders (Meurman et al., 2004; Taylor and Borgnakke, 2008).

A systematic review indicated that people with ID have poorer oral hygiene and a greater prevalence and severity of periodontal disease than the general population in a range of countries (Anders and Davis, 2010). There is a range of potential reasons why people with ID experience poor oral health. The six main factors involved in the aetiology of dental disease (diet and nutrition, oral hygiene, exposure to fluorides, tobacco and alcohol, injury and other acute and chronic medical conditions) will be relevant (Department of Health 2005). People with ID may be more at risk of some of these factors and face additional factors which will impact negatively on their oral health.

Frequent-sugar consumption is the most significant factor in the development of dental decay and poor diet and excessive consumption of acidic foods and drinks can also impact negatively on oral health (Department of Health 2005, 2007). People with ID may not be supported to eat a healthy diet, may require special diets or be malnourished. Frequent sugar intake in drinks and sweet snacks as part of everyday diet, medication and nutritional health interventions, for example sugar based liquid medication, laxatives-and high calorie food supplements, alongside inadequate support around oral hygiene, may increase the risk of tooth decay (Bellis, 2008; Bernal, 2005; BSDH, 2012; Department of Health, 2007). In addition, exaggerated gingival response to some medication can add to the problems of gum inflammation and loss of supporting bone and other medications can reduce saliva flow, reducing the protective role this has in oral health (Scully, 2003).

Moreover, many people with ID experience health problems such as gastroesophageal reflux which increase the risk of dental erosion (Bernal, 2005). 
People with Down's syndrome are more likely to breathe more through the mouth, which can compromise oral health (Bernal, 2005). Non-oral feeders may experience specific complications that will affect oral health $(\mathrm{DoH}, 2007)$. Such conditions can be more prevalent in those with ID who also have physical disabilities (e.g. scoliosis) and those with dysphagia (Chadwick and Jolliffe, 2009).

On a day-to-day basis effective oral hygiene is fundamentally important in influencing oral health. People with oral, facial and bodily developmental differences may have additional needs impacting on daily oral care (Griffiths, 2000; Nunn 2006). Reduced dexterity may lead to ineffective toothbrushing exacerbating problems, such as gum inflammation leading to loss of supporting bone (Anders and Davis, 2010). Oral tactile sensitivity may increase reluctance to engage with toothbrushing and other oral health activities (e.g. flossing), especially if the person has significant cognitive impairments, reducing their comprehension of why the toothbrushing is required. Oral motor difficulties (e.g. hypertonia in people with cerebral palsy) may make toothbrushing more challenging for the person or those who support them as people may bite down on the toothbrush preventing or extending the time needed to provide support (Bernal, 2005).

Many people with ID have increased need for support around establishing and maintaining oral hygiene routines with the majority of oral care and support being provided in a home setting by parents or support workers (Anders and Davis, 2010; Flickert and Ross, 2012). However, those who support people with ID may not recognise the importance of good oral health, especially for people who are edentulous or have few standing teeth (Department of Health, 2007) and evidence suggests that carers' knowledge and practice of how to effectively carry out daily oral healthcare is inadequate (Faulks and Hennequin, 2000; Bernal 2005; BSDH, 2012). Reasons given by caregivers for omitting oral care include, uncooperative individuals, lack of time, staff and equipment, forgetting, and difficulty executing aspects of daily care (e.g. flossing) (Fickert and Ross, 2012).

There may be variations in daily oral health support received in different settings; one study found that adults with ID living with families had more untreated decay and poorer oral hygiene, whilst adults living in residential services had more missing teeth (Tiller et al., 2001). It is possible that the lack of value placed on people with ID having teeth and the challenges in providing dental treatment to this population are such that removal of teeth is viewed as more appropriate and expeditious. Services for people with ID have tended not to make oral hygiene a high priority (Bernal, 2005; Simon et al, 2004) and organisational factors such as the challenge of recruiting, training and retaining high-quality support workers impact upon the oral health of people living in supported accommodation (Ford and Honnor, 2000).

Oral hygiene support, for instance toothbrushing, can be an invasive process. Lack of comprehension regarding why oral care is occurring can, understandably, lead to people with ID not accepting and cooperating with daily oral care (Manley et al., 2000). Moreover, it may be harder to explain why oral care is necessary and to alleviate fears and anxiety around oral care (BSDH, 2012). Resultant lack of daily care may subsequently be followed by reduced recognition of dental/oral problems and pain due to reduced understanding and communication barriers. Potentially, this can result in prolonged periods of oral discomfort and pain, which can, in turn, 
manifest through people's behaviour with increases in challenging behaviours which can further impede daily oral care (for example, face slapping or head banging) (Barr et al., 1999; Turner et al., 2012). In addition, people with ID may face challenges accessing dental services and consequently gaining oral health advice and treatment (BDSH, 2012; Department of Health, 2007; Owens et al., 2011).

Some headway has been made in identifying oral health problems and risk factors for poor oral health and hygiene among people with ID. However, less empirical information is available about daily oral care. Some anecdotal evidence and small scale studies indicate what may facilitate and hinder daily oral care and engagement in brushing of teeth and gums among people with ID. However, there are no larger scale investigations, which specifically focus on the identification of factors that hinder and facilitate daily oral care. Such larger scale research would also have particular benefits including: (i) being more representative and limiting the influence of outliers or extreme cases; (ii) being more likely to find significant differences and relationships that exist, reducing the likelihood of type 2 errors; (iii) allowing comparisons to be made between facilitators and barriers reported for those with different demographic characteristics, support needs or lifestyle circumstances (e.g. residential setting); (iv) reducing the chances of discovery failure and saturation failure around the phenomena of interest in qualitative data; (v) allowing the accumulation of large scale research findings to provide a more accurate overall picture of the phenomena under study (Patel et al., 2003; Sandelowski, 1995).

\section{Study Aim}

This paper presents findings from a large collaborative service development project between local adult learning disability services and the community dental service. The aim of the project was to corroborate and extend previous research about oral health barriers and facilitators and to improve access to dental care services and preventive advice for adults with ID. A dental epidemiological survey was undertaken to add to the existing knowledge regarding the oral conditions present in adults with ID and to identify factors that help and hinder daily oral care and access to dental services for people with IDs. This paper focuses solely on the findings about daily oral care within the residential setting.

\section{METHOD}

\section{Design}

This was a descriptive, phenomenological study. Open ended questions were used to collect the data regarding the lived experiences of daily oral care of people with ID and their carers. These questions were contained within a survey administered via face-to-face or telephone interviews (see Box 1).

\section{INSERT BOX 1 AROUND HERE}

\section{Participant recruitment and data collection}

The participants were people with ID and their family and paid caregivers. A database held by the local commissioning team for specialist community health and 
social care services for adults with ID in an area in the North West of England was used to identify the target population and formed the sampling frame for the study.

\section{INSERT TABLE 1 AROUND HERE}

It was intended that all adults with ID on the database would be contacted for the project. An invitation letter was distributed explaining the purpose of the study and what taking part would entail. Following this, a first follow up telephone call was carried out to answer questions and to check if people wished to take part. Of 1159 people on the database, 576 were contacted within the timeframe allocated for the study and initially agreed to take part. Further telephone calls were then conducted to arrange a time and location to conduct the survey. It was not possible to contact 136 potential participants following five attempts and so they were not included in the study. Of the original 576 potential participants, 440 ultimately took part and of these 372 provided a response to the questions on the survey about the facilitators and barriers to daily oral care. A check made that all carer respondents knew the person with ID well (i.e. had worked with them for over 6 months) and also had experience of supporting them in their daily oral care. The drop in respondents from 576 to 440 was primarily because the available carer had not worked with the person for 6 months or more or had not supported the person with their oral care. Background details about the participants can be found in Table 1.

Comparing the final sample (Table 1) with the background information available for the 1,158 people in the original database reveals that the final sample was roughly equivalent to the database with two exceptions. Age was similar with the database mean age which was 47.83 (SD=14.7). The proportion of females who took part was slightly greater and males were fewer than in the original database (43.3\% and $56.5 \%$ respectively). The biggest difference evident was that the study had disproportionately large amount of participants from public (21.2\% vs. $17.4 \%$ in the population) and private service (33.5\% vs. $11.5 \%$ in the population) residential settings and a small number of those living with family $(28.5 \%$ vs. $48.6 \%$ in the population). Two factors accounted for this discrepancy, first the project was led by statutory services and hence focused initially on those services e.g. people receiving residential and day services, second, family carers were more difficult to access for data collection. Findings should be considered in light of this oversampling from some residential settings. Level of cognitive functioning and mobility were not available from the original database for comparison.

Data were collected jointly by a researcher and a dental clinician who had experience of working with adults with ID. Data were collected face-to-face during the visits or via telephone interview. Despite attempts being made throughout the study to engage people with ID as participants in the data collection, in the main responses came from people supporting those with ID ( $N=287)$. In many instances $(\mathrm{N}=74)$ the carer provided the main responses with either verbal or non verbal verification concurrently provided by the person with ID. In only 11 instances did the person with ID act as sole respondent, in a few instances with minimal support from a caregiver. These were all people with mild to moderate cognitive impairment, who could communicate verbally, and could effectively alternate between sender and 
receiver roles in the questioning exchange. A qualified community dentist carried out oral examinations where possible (i.e. where the person assented to the examination) (See Table 2). Qualitative data was collected face-to-face from the person with ID or carer as part of an interview immediately subsequent to this, with the person with ID present $(\mathrm{N}=316)$. If this was not possible due to time constraints attempts were made to gather the additional information at a later date from caregivers via a telephone interview $(\mathrm{N}=124)$.

\title{
INSERT TABLE 2 AROUND HERE
}

\begin{abstract}
Verbal responses from the face-to-face and telephone interviews were recorded verbatim. Background characteristics were gathered during the interviews or were extracted, where available, from a local service-held database (age, gender and residential circumstances, mobility information). Degree of intellectual disability was gathered from clinically held records. If, during the course of the interview, it became clear that the caregiver or person was having trouble cleaning teeth or accessing dental services the dental clinician conducting the examination provided advice and gave details of a local dentist who could help.
\end{abstract}

Ethical approval was gained for the study (LREC Ref: 03/SM/207) and consent was gained from the person with ID and caregivers during the visits. Information was provided to participants prior to arranging visits to ensure people had sufficient time to consider whether they wished to participate. If, due to the person's cognitive impairment, it was not possible to obtain informed consent, the person's next of kin was asked to agree that they or the person's paid carer could participate and describe the experiences of oral care.

\section{Data analysis and reliability of coding}

Thematic network analysis (Attride-Stirling, 2001) was used to analyse the data. A coding frame was devised for the responses. The authors each developed a list of codes by reading through the responses independently, then these two initial lists were collated and refined through discussion into a single list. These codes were used to segment the textual responses and the themes were abstracted and refined from these segments. To construct the thematic networks the text was arranged into basic themes and, following this, basic themes were grouped into organising themes. Finally the global themes emerged by grouping the organising themes together. The resulting thematic networks were refined and verified by referring back to the original data (See Tables 3 and 4 for the networks). Once finalised, the networks were described and explored. In addition, due to the large sample size, the data was also content analysed (Carley, 1990) which involved looking at every response and determining which of the basic, organising and global themes were contained within them. This was done to provide an indication of the frequency with which each theme had been mentioned as a facilitator and as a barrier to daily oral care. Coding was not mutually exclusive, and responses could contain numerous codes.

To ensure inter-rater reliability, the two coders (authors 1 and 2) content analysed the data from the first $75(20.16 \%)$ respondents independently. This approach has 
been noted to greatly improve the validity (Greenhalgh and Taylor, 1997) and the reliability of the qualitative method (Daly et al., 1992; Ritchie and Spencer, 1993). Inter-rater agreement between the two researchers in terms of classifying the statements regarding the themes relating to oral health facilitators and barriers was found to range between very good and excellent (Kappa range 0.79-1.0, mean agreement 0.98).

Comparisons of the sample to the original database and background characteristics and dental health to thematic frequency data were done via simple statistical comparisons, with test choice dependent on level of measurement and sample size.

\section{RESULTS}

For the questions about daily oral care, 372 people responded to at least one of the two daily care questions; of these, 367 people described what helped when supporting a person with ID to carry out daily oral care and 180 people gave examples of what hindered them. Support to maintain oral hygiene and regular toothbrushing appeared to be in place in many homes and many respondents reported that they currently had no problems in engaging in daily oral care or toothbrushing $(\mathrm{N}=154 ; 41.4 \%)$.

A number of respondents reported that people who wore dentures were managing the care of their dentures with support ( $\mathrm{N}=83 ; 22.3 \%)$, and some caregivers reported that daily oral care and toothbrushing were unnecessary because the person had no teeth or had dentures $(\mathrm{N}=58 ; 15.6 \%)$, demonstrating a substantial level of edentulousness. For some of those with teeth there were also reports of no oral care or toothbrushing occurring, with no plans to address this lack of care apparent $(\mathrm{N}=37 ; 10.0 \%)$. For both of these groups little consideration appeared to be given to oral health issues. From the responses two global themes were identified via the analysis; 'personal and lifestyle influences on daily oral care' and 'social and environmental influences on daily oral care'.

\section{Personal and lifestyle influences on daily oral care}

The reported personal and lifestyle influences on daily oral care were often seen as centring on the person with ID and aspects of their lifestyle and were in the main reported as hindrances to daily oral care. The thematic network for the global theme 'personal and lifestyle influences' is presented in Table 3 along with definitions of the themes with frequencies and illustrative quotations. Influential personal characteristics included cognitive, physical, sensory, behavioural, affective and lifestyle factors.

\section{INSERT TABLE 3 AROUND HERE}

\section{Cognitive factors}

This organising theme incorporated the situations where cognitive processing and impairment affected daily care. Cognitive factors were cited primarily as a hindrance but also as a facilitator of daily oral care. The person with ID not knowing or understanding how to brush their teeth appropriately and maintain their oral health 
was a reported as a difficulty. Some didn't brush adequately, missing teeth and surfaces, whilst others did not brush long enough to be effective or brushed for too long, being unaware of when to stop.

Related to this were reports that the person did not understand why brushing teeth and engaging in oral care was important, this was sometimes mentioned in conjunction with the person having a negative attitude towards toothbrushing, choosing not to brush and/or refusing to be supported around oral care. Linked to inadequate brushing and brushing for too short a time was the difficulty some people had concentrating on and attending to oral care. This was linked to difficulties focusing and attending for the required length of time and being easily distracted.

Finally, the person forgetting to clean their teeth without prompting was also reported as a problematic. This was particularly difficult for people who were more independent in daily oral care and/or lived alone as caregivers may feel they do not need to remind the person or cannot because the support hours do not cover the times when tooth-brushing typically occurs. Conversely, remembering to engage in daily oral care was mentioned in conjunction with self-direction, knowing how to brush their own teeth, being able to follow oral care instructions and having a daily routine; these were all cited as factors which facilitated brushing and oral care.

\section{Physical and sensory factors}

Physical factors were also primarily mentioned as a hindrance; the presence of adequate physical functioning for tooth brushing appeared to be taken for granted and was seldom mentioned as a facilitator of oral care when no physical problems were present. Instead, physical impairments that affected manual dexterity and physical functioning therefore making holding the brush, coordinating tooth brushing and positioning at the sink difficult and, in some cases, impossible were mentioned as preventing independent or semi-independent tooth brushing.

Sensory problems were also reported as an issue. Such problems incorporated people who were highly sensitive and did not like to be touched around their faces or in or around their mouths and those people with sensory impairments that made tooth brushing more difficult (e.g. visual impairments).

A number of oral health problems were reported as interfering with oral care and making tooth brushing more difficult and more distressing for some caregivers and the people with ID. These included problems related to lack of oral care, bleeding/receding gums, loose, sensitive or impacted teeth, exposed roots, build up of plaque and the mouth being painful/sore. Having ulcers and dry mouth, the latter often due to medications, were also noted as impeding oral care. In addition difficulties brushing were mentioned in a small number of cases when the person had cranio-facial and oral tone differences (e.g. high oral muscle tone, tongue thrust), making accessing the teeth or mouth more challenging, and when the person had a diagnosed dysphagia where there were worries about aspiration of toothpaste/mouthwash, with the possible need for suctioning; these made the logistics of oral care more challenging. 


\section{Behavioural factors}

This organising theme represented behaviours exhibited by people with ID that were viewed as affecting daily care. Cooperation was the main personal facilitator of oral care mentioned. Being cooperative was usually mentioned for those receiving significant support around tooth brushing. This was often overlooked as a facilitator; all of those who reported no problems and who fully supported people with their oral care were likely to be experiencing cooperation from those they support, yet only 20 participants explicitly mentioned it.

Obstructive or uncooperative behaviour was the personal factor most often implicated in hindering oral care. These behaviours appeared to happen often because the person did not understand what the requirements of the particular oral care activity were. Examples of such behaviours included the person with ID grinding their teeth, shutting their mouth, biting down on the toothbrush, trying to eat toothpaste, moving their head, and talking during brushing. It also referred to situations where the person would not permit others to support them to clean their teeth or to be in the bathroom with them whilst they were engaging in personal care, but who would not clean their teeth adequately or at all themselves.

A number of behaviours which have been identified as challenging to those providing support were mentioned (e.g. Emerson, 2001) as impeding or preventing daily oral care activity. These included aggressive, self-injurious and socially inappropriate behaviours such as screaming and shouting whilst oral care was taking place. Behaviours attributed to ongoing mental health problems were mentioned rarely, but were sometimes referred to in conjunction with mood as hindering daily oral care.

\section{Affective factors}

This organising theme pertained to the dispositional and emotional influences that helped and hindered toothbrushing. As with the previous personal factors, affect was largely, though not always, mentioned as blocking oral care rather than facilitating it.

The person's mood was said to be an influential facilitator and hindrance in a number of ways. Firstly, mood was often mentioned alongside behavioural issues and fluctuating and variable moods could either facilitate or hinder tooth brushing. Secondly, motivation was linked to mood, with some people described and perceived by their caregivers to be lazy, stubborn and unwilling to look after their oral health. Lack of motivation was sometimes accompanied by mention of poor general personal care and hygiene that went beyond oral care.

Fear referred to the instances where the person was afraid or very anxious around tooth brushing and oral care. In conjunction with a person's unwillingness to cooperate with oral care and a caregiver's concerns and beliefs (see below), such fear and anxiety could increase reluctance to attempt to engage people in oral care amongst caregivers.

Another affective basic theme referred to whether the person liked or disliked daily oral care. Again this was mainly mentioned in terms of things that people disliked; these included toothpaste, mouthwash and their aftertastes, the toothbrush, having 
someone near or around their face, and moving into an appropriate toothbrushing position. This basic theme was often mentioned alongside lack of motivation, uncooperative obstructive behaviour, limited attention span and coaxing people to have their teeth brushed. Affective factors were almost always mentioned alongside behavioural issues that impeded toothbrushing.

\section{Lifestyle factors}

Aspects of people's lifestyles were not mentioned as promoting oral health or increasing the perceived importance of daily oral care; instead, lifestyle factors including smoking, diet and eating sugary foods and regular use of medication negatively affected oral health and led to stained teeth.

\section{Social and environmental influences on daily oral care}

Table 4 details the thematic network for the global theme social and environmental influences and its three associated organising themes: caregiver support, oral care routine, and equipment and adaptations.

\section{INSERT TABLE 4 AROUND HERE}

\section{Caregiver support}

Caregiver support was the most frequently mentioned facilitator of daily oral care for people with ID. There were two main ways in which caregiver support was provided; through the use of interpersonal and observational support strategies and direct help carrying out all or some tooth and gum cleaning. Although less frequently raised, the relationship between the person with ID and caregiver, caregiver concerns, training and advice also impacted on oral care.

Interpersonal and observational support strategies used by caregivers included verbal and physical prompting and instructions to carry out oral care and observation and monitoring to ensure that oral care was being adequately conducted by the individual with ID. Prompting was necessary both to remind people with ID that oral care was necessary and how to carry out oral care. Many people with ID only needed a simple verbal reminder. However, for others, caregivers used a number of strategies to persuade people to carry out oral care including distraction, encouragement, reassurance, coaxing, nagging and promises of rewards. A number of people mentioned bad breath or loss of teeth relating to oral hygiene and the potential impact upon people's social interactions with others. Highlighting this consequence of lack of oral care was sometimes used to persuade people with ID to carry out their daily oral care.

A number of caregivers provided direct support carrying out all or some of the cleaning of teeth and gums or helping with part of the oral care routine. This was deemed necessary in instances where the person with ID could not physically carry out their own oral care due to poor co-ordination, physical or sensory impairments or because the person with ID could not remember how to carry out oral care. Often caregivers would then provide further cleaning once the individual had cleaned their own teeth to ensure that teeth were adequately cleaned. Sometimes it was 
necessary for more than one caregiver to simultaneously provide support during oral care.

Other issues relating to caregiver support which were less frequently raised but could facilitate or hinder daily oral care were also reported. The first of these concerned whether people with ID were familiar with the person providing support with daily oral care and whether this influenced their cooperation. The second pertained to having sufficient time during the day whilst fulfilling other support roles to support oral care.

Caregivers expressed concerns and beliefs which impeded daily oral care. Some were worried that brushing teeth or gums whilst the individual had bleeding gums would hurt the person they were supporting. Others were concerned that the person would become 'hysterical' or aggressive if they tried to support them to clean their teeth. Negative prior experiences meant that caregivers could be reluctant to encourage or help with oral care. Occasionally there was a sense that caregivers did not feel that oral care was important enough to persevere with in light of the prior difficulties experienced, that 'it wasn't worth the upset'.

Caregivers occasionally mentioned the role of training and advice. Some caregivers wanted advice and support around how to support someone to clean their teeth and improve daily oral care.

\section{Equipment and adaptations}

Equipment and adaptations were the second most commonly mentioned environmental influence on oral care. The type of toothbrush, toothpaste and mouthwash used could make a difference both to how effectively oral care was carried out and the willingness of people with ID to co-operate with oral care routines.

The type of toothbrush used was important. Some people with ID and caregivers preferred using a manual toothbrush whilst others preferred using an electric (or battery) toothbrush, occasionally people used both. This factor co-occurred with oral sensitivity as a hindrance. Some people preferred a soft toothbrush or a toothbrush with a small head. Sometimes people with ID did not clean their teeth properly with a manual toothbrush or were reluctant to change their toothbrush. Whilst many caregivers believed that electric toothbrushes would improve how well teeth were cleaned, a number of people were reported to dislike, or even be scared of, electric toothbrushes because of the noise or vibration they make. Such fear and dislike meant that they might not co-operate with toothbrushing.

Toothpaste was frequently referred to as an important component of oral care and rarely led to any problems. Many people used mouthwash as part of their oral care routine. Whilst many people reported no problems using mouthwash, occasionally people with ID would swallow or drink it, which could make caregivers more reluctant to use it.

Two caregivers used suction tools because they supported a person with dysphagia with problems swallowing liquid and a saliva build-up, with concerns than aspiration of saliva and toothpaste would occur. Whilst it could be awkward having the toothbrush and suction tool in the mouth simultaneously this did not reportedly 
cause major problems and caregivers had been shown how to use the suction tool by Speech and Language Therapists.

There was one report of the physical environment having been adapted to make it easier for oral care to take place; this was in the case of a wheelchair user where 'everything was at a level that she could get to it.' This may, once again, represent omission of a facilitator that is taken for granted and hence not explicitly mentioned.

\section{Individualised oral care routine}

The final environmental influence on daily oral care emerging from the analysis was daily toothbrushing and oral care routine. Once again, this was usually discussed in terms of helping rather than hindering oral care and overlapped considerably with the direct support theme. Nevertheless, aspects of having a regular daily routine were commonly mentioned as facilitative factors. Conversely, a clear hindrance in achieving daily oral care for some people was that they did not have an oral care routine in place.

For many people with ID oral care formed part of a person's daily routine and oral care was simply something which they regularly did. People would clean their teeth at particular times of the day, for example in the morning and/or evening, after meals or when they had a bath. Being part of a daily routine was an important way of ensuring that oral care took place and made it easier to remember when to carry out oral care.

Instructions and support from caregivers could play an important part in the daily oral care routine. Caregivers would remind people that it was time to clean their teeth through verbal reminders or by putting toothpaste onto the toothbrush. Seeing other people who they lived with or staff cleaning their teeth could also remind people to carry out their own oral care. Caregivers would remind people how to carry out oral care routines in a variety of ways. These included modelling to show people how to clean their teeth, placing their hand over the person with ID's hand and taking them through cleaning their teeth and giving verbal instructions.

Location could form an important part of the oral care routine. A location where someone felt relaxed was mentioned, such as in bed or in a bath. Having no distractions and oral care items in the 'correct' place was important for one individual. At other times location was integrated into the routine - for example sitting on the toilet next to the sink, or cleaning teeth in the shower.

How a caregiver approaches people with ID and the caregiver's body language could also influence the success of oral hygiene routines. One caregiver was aware that the person they supported needed space so would sit him down and then stand behind him. Another person needed caregivers to speak less and make no eye contact with her if her oral care routine was to be a success.

Finally, the individualised way in which oral care and toothbrushing was carried out was also an important part of the oral care routine. For instance, using short bursts of brushing, being very quick, and using as little pressure or hand movement as possible were strategies some caregivers had found useful when supporting someone to clean their teeth. 


\section{Comparisons with those who indicated they had no problems with oral care}

To further explore the differences between those who reported problems around oral care and those who did not a series of comparisons were conducted. Comparison of the characteristics of the participants with ID where no problems in daily care were reported revealed that those people had a lower degree of ID $(t(368)=2.38$, $\mathrm{p}=.02$; No problem mean $=2.38(\mathrm{SD}=.82)$, oral care issues reported (mean $=2.58$ $(S D=.83)$ ) and were more mobile (Chi-square $(1)=8.36, p=.004)$ compared to those who reported issues around oral care. Age was not related to the reporting of problems $(\mathrm{t}(367)=-2.16, \mathrm{p}=.83)$. Though statistical comparison proved nonsignificant for residential setting (Chi-square $(4)=3.95, p=.41)$, issues around oral care were more often reported in family, independent sector and public sector group homes (60-62\%) than in adult placements (55\%) and independent living $(50 \%)$ settings. A trend was found for sex (Chi-square $(1)=3.71, p=.054)$ with issues more frequently reported for males $(63 \%)$ compared with females $(53 \%)$.

The more personal and lifestyle factors hindering (Chi-square $(4)=133.02, p=.001$ ) and social and environmental factors facilitating oral care (Chi-square $(3)=9.97$, $p=.019)$ the less likely the respondent was to report no problems around daily care. Considering the facilitators of daily oral care, caregiver support was reported as a facilitator significantly more by those who reported issues around daily oral care (Chi-square $(1)=5.14, p=.023$ ). Comparison of the use of the specific support strategies that reportedly facilitated daily care revealed no significant differences between those who reported problems and those who did not in the use of interpersonal and observational strategies (Chi-square $(1)=.11, p=.74$ ) or caregiver training and advice (Chi-square(1)=.07, $p=.79$ ). Direct support for oral care however was used more as a strategy by those who reported challenges (Chisquare $(1)=14.32, p=.001$ ). 'Taking time, persevering and having patience' and 'being familiar to the person' were both used more by those who reported challenges around daily care but not to a statistically significant degree (Fisher's exact, $p=.08$ and $p=.27$ respectively).

Equipment and environmental adaptation was reported less as a facilitator used by those who also reported no problems, but not to a significant degree (Chisquare $(1)=2.06, p=.15)$. Looking at the individual adaptations, using a specific type of toothbrush (Chi-square $(1)=.24, p=.63$ ) and toothpaste (Chi-square $(1)=.5, p=.48$ ) did not significantly differ between the two groups. Using mouthwash however, was reported significantly more by those who had issues around daily care (Chisquare $(1)=10.12, p=.001)$.

Having an individualized oral care routine was also reported less by those reporting no problems but again not to a significant degree (Chi-square $(1)=3.29, p=.07$ ). Having a routine was reported to be used to similar degree by both those who did and did not report problems around oral care (Chi-square $(1)=.4, p=.85$ ). Having a specific location (Fisher exact, $p=.053$ ), an individualized approach (Fisher exact, $p=.27$ ) and approaching the person in a particular way (Fisher exact, $p=.082$ ) were all utilized more by those reporting issues around oral care, though not to a statistically significant degree. Instruction and helping during oral care was reported significantly more by this group (Chi-square $(1)=4.15, p=.04$ ). 
Comparing those who did and did not report problems on the oral health and examination variables indicated that for those people where no problems were reported a full examination was significantly more likely to be possible (Chisquare $(2)=18.42, p=.001$ ) and food debris was less likely to be present, though this latter comparison only approached statistical significance (Chi-square(2) $=3.68, p=.055)$. The oral health measures, inflammation (Chi-square $(1)=.51, p=.48$ ), periodontal conditions (Chi-square $(1)=2.09, p=.15$ ) and current active caries (Chisquare $(1)=.17, p=.68$ ) did not differ statistically between the two groups.

\section{Comparison of oral care facilitators \& hindrances by residential setting}

Comparison of differences between residential homes in terms of the facilitators and barriers extracted from the qualitative accounts revealed no significant differences between the residential settings for the social and environmental organising themes equipment and environmental strategies and individualised care routine $(p=.28$ and .19 respectively). The organising theme direct carer support was reportedly used significantly more in family $(41.5 \%)$, public provider $(36.7 \%)$ and independent provider $(41.6 \%)$ settings compared with adult placement $(26.7 \%)$ and independent living (11.1\%) settings (Chi-square $(4)=11.19, p=.024)$.

For the personal and lifestyle factors reported as impeding oral care only the cognitive factors (i.e. understanding, attending to and remembering oral care) significantly differed across residence (Chi-square $(4)=10.04, p=.04$ ). Cognitive hindrances were mentioned more in family homes $(23.6 \%)$ than independent living $(18.7 \%)$ and adult placement (16.7\%) settings, with independent $(11.2 \%)$ and public provider $(8.9 \%)$ homes reporting these factors least. No significant differences were found by setting for physical, affective, behavioural and lifestyle hindrances to oral care (All $p>.05)$.

Thus it appears that support needs linked to cognitive factors, which are likely to vary systematically across residential settings, may underpin the different facilitators used and barriers faced. This has implications for the types of support people with ID and their carers are offered in different settings. For example, forgetting to brush was mentioned more often in independent living and family settings, hence reminding people would be a useful strategy in these residential settings.

\section{DISCUSSION}

The findings from this study corroborate and extend previous findings regarding the barriers to daily oral care and the factors that promote oral care. The findings reveal that factors that facilitate and hinder daily toothbrushing and oral care are many and varied, ranging from individual factors to caregiver support and other environmental factors. The complex interactions between these various factors impacts on the experience and effectiveness of the oral health routines of people with ID.

A strong focus on personal characteristics as barriers was evident; in particular the presence of behaviours considered obstructive to daily care, a dislike of oral care, pre-existence of oral health problems, problems remembering and understanding how to brush and problems coordinating and holding the toothbrush. These factors corroborate previous findings regarding barriers to daily care (e.g. Anders and Davis, 2010; Barr et al., 1999; Bernal, 2005; Flickert and Ross, 2012; Griffiths, 2000; 
Nunn 2006; Turner et al., 2012) but also extend these findings by providing empirical support for additional factors including understanding, memory, attention, dysphagia and personal preference of the person with ID as factors affecting oral healthcare.

Some respondents reported that the intellectually disabled person chose not to brush their teeth because they either did not like it or did not see the reason for brushing, these people tended to be less cognitively impaired. This impediment to daily oral care highlights the tension that often exists between self-determination and engaging in healthful behaviours. The underlying reasons for choosing not to brush were not explored in detail in this study. It is likely that historical experiences, affect, temperament, attitudes, and support all play some role in such choice making, further qualitative research could elucidate this.

Cooperation and being physically and cognitively able to engage in oral care were commonly mentioned as facilitators. It was however, apparent that when understanding, physical dexterity, cooperation, motivation and finding oral care unproblematic or even enjoyable occurred, these were less often mentioned by respondents. These omissions are likely to reflect the existence of a routine of oral care for these individuals and the lack of deconstruction of the individual factors that facilitated oral care.

The findings also demonstrate the role environmental, attitudinal and support related factors can play in both hindering and facilitating oral care. The findings provide empirical support for the important role of caregiver support highlighted by other studies (Fickert and Ross, 2012, Simon et al., 2004, Faulks and Hennequin, 2000). This study provides further information about the different types of strategies used by caregivers and demonstrates that caregivers draw on a range of interpersonal and observational support strategies as well as providing direct support carrying out all or part of a person's oral hygiene. The findings confirm the importance of identifying appropriate oral health equipment (toothbrush, toothpaste and mouthwash) that is acceptable to people with ID (Simon et al., 2004), and the importance of oral care forming part of a person's daily routine. Flossing has been highlighted as being a difficult part of oral hygiene for caregivers to support (Fickert and Ross, 2012), yet this issue was not raised in this study. It is possible that the importance of flossing and strategies to carry out flossing on another person has not been emphasised to caregivers in the locality of this study.

The use of giving information about the social consequences of not maintaining oral hygiene as a method of promoting engagement with daily care suggests that possible social, interactional and reputational consequences of having poor oral health and cosmetically poor looking teeth can be important to people with ID. Prior research has suggested that treatment has differed for people with ID, with more likelihood of removal of teeth rather than restoration, with the implication that the social consequences of oral care and treatments for people with ID may seem less important to dental practitioners than the consequences for their typically developing peers. This study does not support this view and advocates for greater equivalence of treatment. 
Attribution of personal characteristics as the primary impediments to oral care may reflect the lack of recognition or adoption of the social model of disability amongst caregivers (Barnes and Mercer, 2004), and may demonstrate that further support strategies need to be put in place to overcome barriers to adequate daily care. Although cognitive, physical, behavioural and affective factors have been classified here as personal characteristics, it is important to remember that they actually represent the interplay between individual impairments and environmental support systems. For example, not remembering would not be an issue if the person was reminded. Many barriers described as personal characteristics could be reconceptualised as a breakdown in support systems and reflect insufficient knowledge held by and/or resources available to those supporting people with ID to manage and maintain their oral health.

Breakdowns in support are likely to be exacerbated by high levels of staff turnover reported in ID services (Tiller et al., 2001). New staff may feel ill equipped to engage in unfamiliar support requiring close physical contact and may be unfamiliar to the person with ID, which may make them less receptive to receiving support, triggering affective and behavioural related barriers and preventing carers from developing experience in supporting or providing oral health care. One of the main challenges in recruitment to participate in this study was the lack of available respondent caregivers who had worked with the person with ID for more than 6 months, indirectly implying high levels of staff turnover.

There was a cycle of impediment to oral care evident in some accounts. For instance an individual who did not understand or like oral care, who was therefore less likely to cooperate or engage in oral care and did not receive support to enable engagement. They then went on to experience increased oral pain and bleeding, which, in turn, made it difficult for them to allow a carer near their mouth to clean their teeth. This led to the carer worrying about the amount of blood in the person's mouth when they did manage to engage in brushing. Consequently, these difficulties resulted in less oral care and likely exacerbation of poor oral health. Thus more support for daily care for those who are resistant is indicated to prevent such cyclical decline.

Although many respondents reported no problems in undertaking daily oral care and toothbrushing, it is unclear whether this is an accurate reflection of their experiences of no problems with good oral care in place, whether respondents were reluctant to divulge information about oral care, whether they did not know what constitutes adequate daily oral care or whether it was a combination of these. Comparisons indicated that daily oral care occurring in a specific location, provision of direct support, instruction and help and the use of mouthwash appeared the most significant strategies for facilitating daily oral care for those who report problems. The findings also indicate that reporting no problems in oral care does not necessarily reflect better oral health for those being supported. It is of concern that some caregivers believed that oral care was unnecessary for those without any teeth as absence of such care could potentially impact negatively on both health and social wellbeing.

There appeared to be a lack of oral health care routines in place for a substantial minority of people with teeth, as well as the edentate. Overlooking and/or not 
prioritising oral health care may also reflect the tension between competing requirements of supporting people with ID. People in supporting roles are often seen as responsible for promoting self-determination and independence alongside providing sufficient individualised support for the person and engaging them in domestic tasks as developmental opportunities and, if it is a family carer, they also require time to tend to their own needs too. Such competing demands are likely to lead to unspoken/hidden needs (i.e. those the person cannot communicate about) going unnoticed and remaining unmet. Though this is supported by the lack of time respondents reported, further work is needed to illuminate support situations where daily oral care is overlooked or abandoned.

Instances of good collaborative working and problem solving skills around oral healthcare, including developing and introducing environmental supports for the person with ID, and the use of equipment, routines, instruction and support strategies were apparent. However, the comments made clearly indicate oral care can be a distressing experience for some people with ID and their caregivers and that caregivers needed support to introduce and improve oral care routines. Carers mentioned concerns about pain and bleeding which might deter them pursuing effective oral health care and there were some instances where dentists had allayed their fears by explaining that such bleeding was not a reason not to engage in toothbrushing. These findings indicate the need for more awareness-raising and training for caregivers around the importance of oral health and hygiene and strategies to engage people with ID in oral care (cf. Grant et al., 2004; Lange et al, 2000; Faulks and Hennequin, 2000; Fickert and Ross, 2012; Mac Giolla Phadraig et al., 2013).

Individualised routine daily care was a key facilitator mentioned by the respondents in this study, suggesting that individualised support programmes about oral healthcare for people with ID who are reluctant could be beneficial. Previous work has also advocated an individualised approach to oral health management (e.g. Simon et al., 2004), emphasising the need for people with ID to be central to the process and that their choices need to be considered in planning how oral care is conducted. The findings here support this approach and that adults with ID, especially those with fewer support needs, require tailored information about the activities involved in oral care and the consequences of their oral health care choices. Gathering more information about why people like or dislike oral care and identifying alternative methods and equipment is indicated. Methods of desensitisation for adults who are fearful or find oral care aversive need to be introduced and evaluated.

This study highlights the complex interplay between the person with ID, the environment and equipment and the support provided in providing daily oral care. Given this complexity it is important that a strategic, well-planned, proactive and preventive approach is taken to oral health by organisations and that training and engagement of caregivers and people with ID occurs. Such training needs to ensure that oral health is viewed as much more than simply ensuring dental appointments occur at appropriate intervals (BSDH, 2012; Simon et al., 2004). There is a need to identify and evaluate effective ways of reaching and engaging with people with ID and family members to increase their awareness of the importance of daily oral car, 
to improve their knowledge of how to support and improve daily oral care routines and to access guidance and support.

Primary care and multidisciplinary Community Learning Disability Teams (CLDTs) have an important role to play. Including questions regarding oral health and daily oral care in health assessments and checks would help to identify people who may be experiencing difficulties. CLDTs usually include a range of health professionals who could play useful part in helping to improved daily oral care. For example, psychology could help manage anxiety around oral care and SLT could aid carers to better communicate and guide people with LD during oral care.

At a strategic level improved communication and collaborative planning of oral health management between the oral health system and ID services is being planned. Locally, the study findings supported the appointment of a community dentist with a specialism in ID. The role and impact of specialist community dentists is an area for future evaluation research. In addition, all dental practitioners would benefit from training and awareness-raising about potential barriers and facilitators to oral care experienced by people with ID and their carers and from asking people with ID and caregivers about their oral care routine.

The study presented here is limited by the local nature of the research. Also it did not explore in great depth the experiences of daily health care by people with ID and reasons why people with ID may not engage with daily oral care from the perspectives of people with ID. Furthermore, there may be systematic differences in barriers faced by those who have supported a person with ID for over 6 months and knows them relatively well when compared to a person who has more recently taken on the caregiving role. More research is needed on the impact of oral health training for both caregivers and people with learning disabilities and the best way to improve and maintain oral care knowledge and skills.

\section{Declaration of Interest}

The authors report no declarations of interest.

\section{Keywords}

Intellectual disability, dental health, oral care, individualised support, Training, Qualitative

\section{REFERENCES}

Anders, P.L. and Davis, E. L. (2010). Oral health of patients with intellectual disabilities: A systematic review. Special Care Dentistry, 30(3),110-11.

Attride-Stirling, J. (2001). Thematic networks: an analytic tool for qualitative research. Qualitative research, 1(3), 385-405.

Barnes, C. and Mercer, G. (2004) Implementing the Social Model of Disability: Theory and Research. Leeds: The Disability Press.

Barr, O., J. Gilgunn, et al. (1999). Health screening for people with learning disabilities by a community learning disability nursing service in Northern Ireland. Journal of Advanced Nursing, 29(6), 1482-1491. 
Bernal, C. (2005). Maintenance of oral health in people with learning disabilities. Nursing Times, 101(6), 40-42.

Bellis, K. (2008). A healthy mouth: oral healthcare for people with PMLD. PMLD Network (Retrieved from

http://www.pmldnetwork.org/resources/Oral_healthcare_PMLD_factsheet.pdf, 25/03/2014).

British Society for Disability and Oral Health (2012). Clinical Guidelines and Integrated Care Pathways for the Oral Health Care of People with Learning

Disabilities. Faculty of Dental Surgery, The Royal College of Surgeons of England Carley, K. (1990). Content analysis (pp. 725-730). The encyclopedia of language and linguistics. Edinburgh: Pergamon Press.

Chadwick, D. D. and Jolliffe, J. (2009). A descriptive investigation of dysphagia in adults with intellectual disabilities. Journal of Intellectual Disability Research, 53(1), 29-43.

Daly, J., McDonald, I. \& Willis, E. (eds.) (1992) Researching Health Care: designs, dilemmas, disciplines. London: Routledge.

Department of Health (2005) Choosing Better Oral Health: an oral health plan for England. London: HMSO.

Department of Health. (2007). Valuing People's Oral Health: A good practice guide for improving the oral health of disabled children and adults. London: HMSO.

Emerson, E. (2001). Challenging behaviour: analysis and intervention in people with intellectual disabilities. Cambridge, Cambridge University Press.

Emerson, E., S. Baines, et al. (2012). Health Inequalities and People with Learning Disabilities in the UK: 2012, Improving Health and Lives: Learning Disabilities Observatory.

Faulks, D., and Hennequin, M. (2000). Evaluation of a long-term oral health program by carers of children and adults with intellectual disabilities. Special Care in Dentistry, 20, 199-208.

Fickert, N. A. and D. Ross (2012). Effectiveness of a Caregiver Education Program on Providing Oral Care to Individuals with Intellectual and Developmental Disabilities. Intellectual and Developmental Disabilities, 50(3), 219-232.

Fiske, J., Griffiths, J., Jamieson, R. and Manger, D. (2000). Guidelines for oral health care for long-stay patients and residents. Gerodontology, 17, 55-64.

Ford, J. and Honnor, J. (2000). Job satisfaction of community residential staff serving individuals with severe intellectual disabilities. Journal of Intellectual and Developmental Disability, 25, 343-362.

Gallagher, J. and Scambler, S. (2012). Disability and Oral Health, Learning Disabilities, Dr. Wichian Sittiprapaporn (Ed.), ISBN: 978-953-51-0269-4, InTech, Available from: http://www.intechopen.com/books/learning-disabilities/disability-andoral-health.

Grant, E., Carlson, G. et al. (2004). Oral health for people with intellectual disability and high support needs: positive outcomes. Special Care Dentistry, 24(2), 70-79. Greenhalgh, T., \& Taylor, R. (1997). Papers that go beyond numbers (qualitative research). BMJ: British Medical Journal, 315(7110), 740.

Griffiths, J. E. (2000). Guidelines for oral care services for people with disabilities: Disability and oral care, World Dental Press.

Lange, B., C. Cook, et al. (2000). Improving the oral hygiene of institutionalized mentally retarded clients. The Journal of Dental Hygiene, 74(3), 205-209.

Mac Giolla Phadraig, C., Guerin, S. et al. (2013). Train the trainer? A randomized controlled trial of a multi-tiered oral health education programme in community- 
based residential services for adults with intellectual disability. Community Dentistry and Oral Epidemiology, 41, 182-192.

Manley, M.C.G., Sleyy, A.M. and Hamilton, A.G. (2000). Dental Treatment for People with Challenging behaviour: General Anaesthesia or sedation? British Dental Journal, 188(7), 358-360.

Meurman, J. H., M. Sanz, et al. (2004). Oral Health, Atherosclerosis, and

Cardiovascular Disease. Critical Reviews in Oral Biology and Medicine, 15(6), 403413.

Nunn, J. H. (2006). The burden of oral ill health for children. Archives of Disease in Childhood, 91, 251-3.

Owens, J., Mistry, K. and Dyer, T. A. (2011). Access to dental services for people with learning disabilities: Quality care? Journal of Disability and Oral Health, 12, 1730.

Patel, M., Doku, V., and Tennakoon, L. (2003). Challenges in recruitment of research participants. Advances in Psychiatric Treatment, 9, 229-238.

Ritchie, J., \& Spencer, L. Qualitative data analysis for applied policy research. In Bryman, A. \& Burgess, R. (eds.) (1994) Analysing Qualitative Data. London: Routledge. 173-194.

Sandelowski, M. (1995). Sample size in qualitative research. Research in Nursing \& Health, 18, 179-183.

Scully, C. (2003). Drug effects on salivary glands: dry mouth. Oral diseases, 9, 165176.

Simon, M.A., Cullen-Erickson, M. et al. (2004). The Experiences and Perceptions of Unit Managers in Facilitating Oral Health in Adults with Intellectual Disability. International Journal of Disability, Community and Rehabilitation, 3(4).

Taylor, G. W. and W. S. Borgnakke (2008). Periodontal disease: associations with diabetes, glycemic control and complications. Oral Diseases, 14(3), 191-203. Tiller, S., K. I. Wilson, et al. (2001). Oral health status and dental service use of adults with learning disabilities living in residential institutions and in the community." Community Dental Health, 18(3), 167-171.

Turner, S., E. Emerson, et al. (2012). Making Reasonable Adjustments to Dentistry Services for People with Dentistry Services for People with Dentistry Services for People with Learning Disabilities, IHAL: Learning Disabilities Observatory. 


\section{Tables}

Box 1: Questions used to gather the qualitative data

Initial question:

1. How do you find cleaning your/(persons name's) teeth each day?

If no facilitators or barriers were forthcoming from the ensuing discussion participants were asked specific questions regarding facilitators or barriers:

1. Is there anything that...

helps you clean your teeth?

helps you to support (persons name) to clean their teeth?

helps when you are cleaning (persons names) teeth?

2. Is there anything that...

hinders you cleaning your teeth?

prevents you from supporting (persons name) to clean their teeth)

prevents or gets in the way when you are cleaning (persons names) teeth?

Questions were adapted based upon who was providing the information (i.e. person with intellectual disabilities or caregiver) and how oral care support was provided. 
Table 1: Participant background Information

\begin{tabular}{|c|c|c|c|}
\hline Background Variable & Categories & $\mathbf{N}$ & $\%$ \\
\hline $\begin{array}{l}\text { Sex } \\
\left(N=372^{\mathrm{a}}\right)\end{array}$ & $\begin{array}{l}\text { Male } \\
\text { Female }\end{array}$ & $\begin{array}{l}159 \\
213\end{array}$ & $\begin{array}{l}42.7 \\
57.3\end{array}$ \\
\hline $\begin{array}{l}\text { Residence } \\
(\mathrm{N}=372)\end{array}$ & $\begin{array}{l}\text { Public sector group home } \\
\text { Private sector group home } \\
\text { Family home } \\
\text { Adult Placement } \\
\text { Independent } \\
\text { Missing }\end{array}$ & $\begin{array}{r}79 \\
125 \\
106 \\
30 \\
27 \\
5\end{array}$ & $\begin{array}{r}21.2 \\
33.6 \\
28.5 \\
8.1 \\
7.3 \\
1.3\end{array}$ \\
\hline $\begin{array}{l}\text { Level of Cognitive Impairment } \\
(\mathrm{N}=370)\end{array}$ & $\begin{array}{l}\text { Mild/Borderline } \\
\text { Moderate } \\
\text { Severe } \\
\text { Profound }\end{array}$ & $\begin{array}{r}41 \\
144 \\
145 \\
40\end{array}$ & $\begin{array}{l}11.1 \\
38.9 \\
39.2 \\
10.8\end{array}$ \\
\hline \multirow[t]{2}{*}{$\begin{array}{l}\text { Physical functioning } \\
(\mathrm{N}=371)\end{array}$} & $\begin{array}{l}\text { Mobile } \\
\text { Not mobile }\end{array}$ & $\begin{array}{r}315 \\
56\end{array}$ & $\begin{array}{l}84.7 \\
15.1\end{array}$ \\
\hline & & Mean & SD \\
\hline $\begin{array}{l}\text { Age in years } \\
(\mathrm{N}=372)\end{array}$ & & 46.1 & 14.6 \\
\hline
\end{tabular}

${ }^{\mathrm{a}}$ Missing data ranged from 0 to $2(0.54 \%)$ cases.

Table 2: Oral health of participants with ID

\begin{tabular}{|c|c|c|c|}
\hline Oral Health Variable & & $\mathbf{N}$ & $\%$ \\
\hline Oral Healthcare & & & \\
\hline Received dental care in & st year & 273 & 73.4 \\
\hline Examination Conducted & Full & 302 & 81.2 \\
\hline & Partial, limited examination & 38 & 10.2 \\
\hline & Examination refused / not possible & 32 & 8.7 \\
\hline Oral Health $\left(N=340^{a}\right)$ & & & \\
\hline Gum Inflammation prese & & 70 & 20.6 \\
\hline $\begin{array}{l}\text { Any periodontal conditio } \\
\text { inflammation } \& / \text { or tooth }\end{array}$ & $\begin{array}{l}\text { ent (Gum } \\
\text { v) }\end{array}$ & 74 & 21.8 \\
\hline Oral Cleanliness - debri & ent & 30 & 8.8 \\
\hline Current active untreated & present & 23 & 6.8 \\
\hline Edentulousness & & 74 & 21.8 \\
\hline Insufficient functional toc & tacts & 172 & 50.6 \\
\hline Prosthesis worn (full or $\mathrm{k}$ & denture) & 55 & 16.2 \\
\hline
\end{tabular}

${ }^{\mathrm{a}}$ Oral health based on $\mathrm{N}=340$, where a limited or full examination was conducted 
Table 3: Showing the organising and basic themes for Global Theme 1 - Personal and lifestyle influences on daily oral care, the frequency with which each was reported and illustrative quotations

\begin{tabular}{|c|c|c|c|c|c|c|}
\hline \multirow{2}{*}{$\begin{array}{l}\text { Global Theme } 1 \text { - Personal \& } \\
\text { Lifestyle Influences on Daily } \\
\text { Oral Care } \\
\text { Organising \& basic themes }\end{array}$} & \multirow[t]{2}{*}{$\begin{array}{l}\text { Definition of Organising and } \\
\text { Basic Themes }\end{array}$} & \multicolumn{2}{|c|}{$\begin{array}{l}\text { Facilitates } \\
\text { daily oral } \\
\text { care } \\
(\mathrm{N}=367)\end{array}$} & \multicolumn{2}{|c|}{$\begin{array}{l}\text { Hinders } \\
\text { daily oral } \\
\text { care } \\
(\mathrm{N}=180) \\
\end{array}$} & \multirow[t]{2}{*}{ Illustrative Quotations } \\
\hline & & $\mathbf{N}$ & $\%$ & $\mathbf{N}$ & $\%$ & \\
\hline $\begin{array}{l}\text { 1. Organising theme: } \\
\text { Cognitive Factors }\end{array}$ & $\begin{array}{l}\text { The facilitator or barrier relates } \\
\text { to cognitive factors }\end{array}$ & 13 & $3.5^{\mathrm{a}}$ & 56 & 31.1 & \\
\hline $\begin{array}{l}1.1 \text { Understanding how to } \\
\text { brush teeth \& maintain oral } \\
\text { health }\end{array}$ & $\begin{array}{l}\text { Presence/absence of under- } \\
\text { standing of how to maintain oral } \\
\text { health \& brush teeth }\end{array}$ & 0 & 0.0 & 21 & 11.7 & $\begin{array}{l}\text { "John can hold the brush but does not know what } \\
\text { is skin and what is tongue." } \\
\text { "Dominic is very reluctant to brush or to open his } \\
\text { mouth wide l'm not sure he understands." }\end{array}$ \\
\hline $\begin{array}{l}1.2 \text { Understanding why it is } \\
\text { important to brush }\end{array}$ & $\begin{array}{l}\text { Presence or absence of under- } \\
\text { standing of why it is important to } \\
\text { maintain oral health }\end{array}$ & 0 & 0.0 & 7 & 3.9 & $\begin{array}{l}\text { "I (Mum) struggle getting him to do it, to under- } \\
\text { stand why it's important, it's an ongoing battle." }\end{array}$ \\
\hline 1.3 Attention and concentration & $\begin{array}{l}\text { Ability to concentrate \&/or attend } \\
\text { to oral care \& toothbrushing }\end{array}$ & 0 & 0.0 & 6 & 3.3 & $\begin{array}{l}\text { "Martin does clean his teeth ... but only briefly. He } \\
\text { has a lack of attention span." } \\
\text { "She does not spend enough time brushing them } \\
\text { herself, she gets bored after two minutes." }\end{array}$ \\
\hline 1.4 Memory & $\begin{array}{l}\text { Remembering/forgetting to clean } \\
\text { teeth \& engage in oral care }\end{array}$ & 13 & 3.5 & 30 & 16.7 & $\begin{array}{l}\text { "I would like someone to remind me but I live on } \\
\text { my own with no-one here when I brush my teeth" } \\
\text { "He doesn't brush very often, keeps forgetting. He } \\
\text { needs prompting." } \\
\text { "He has a routine and doesn't forget. He cleans } \\
\text { very thoroughly." }\end{array}$ \\
\hline $\begin{array}{l}\text { 2. Organising theme: } \\
\text { Physical \& Sensory Factors }\end{array}$ & $\begin{array}{l}\text { The facilitator or barrier relates } \\
\text { to physical factors }\end{array}$ & 2 & 0.5 & 44 & 24.4 & \\
\hline $\begin{array}{l}\text { 2.1 Manual dexterity and } \\
\text { physical coordination. }\end{array}$ & $\begin{array}{l}\text { Manual dexterity and physical } \\
\text { coordination affecting brushing }\end{array}$ & 2 & 0.5 & 11 & 6.1 & $\begin{array}{l}\text { "Mark has little coordination so he can't brush his } \\
\text { own teeth." } \\
\text { "She needs prompting \& help cleaning her teeth } \\
\text { as she cannot coordinate her hand, she can do } \\
\text { the right to left side well but not left to right. She }\end{array}$ \\
\hline
\end{tabular}




\begin{tabular}{|c|c|c|c|c|c|c|}
\hline & & & & & & $\begin{array}{l}\text { opens her mouth lovely \& puts her teeth together } \\
\text { when I need to clean front of her teeth." }\end{array}$ \\
\hline $\begin{array}{l}\text { 2.2 Cranio facial \&/or oral } \\
\text { differences }\end{array}$ & $\begin{array}{l}\text { Cranio facial \&/or oral differences } \\
\text { affect oral care }\end{array}$ & 0 & 0.0 & 5 & 2.8 & $\begin{array}{l}\text { "...has been shown how to clean teeth but } \\
\text { struggles a bit with the process, especially as } \\
\text { teeth are so small." }\end{array}$ \\
\hline 2.3 Sensory issues & $\begin{array}{l}\text { Sensitivity to touch around the } \\
\text { face \& in or around the mouth } \\
\text { area. Sensory impairments. }\end{array}$ & 0 & 0.0 & 6 & 3.3 & $\begin{array}{l}\text { "He won't let anyone touch his face or mouth. It's } \\
\text { always been the case. He pushes you away } \\
\text { when you touch his face." } \\
\text { "Does not like battery toothbrush because of the } \\
\text { noise - her sight problems make brushing more } \\
\text { difficult." }\end{array}$ \\
\hline $\begin{array}{l}2.4 \text { Existing oral health } \\
\text { problems }\end{array}$ & $\begin{array}{l}\text { Existing oral health problems } \\
\text { affects daily care and may cause } \\
\text { pain (e.g. bleeding gums, } \\
\text { sensitive teeth, ulcers) }\end{array}$ & 0 & 0.0 & 21 & 11.7 & $\begin{array}{l}\text { "He has sensitive gums, so it's very painful for } \\
\text { him. He suffers all the time with ulcers." } \\
\text { "She has sore and bleeding gums. She sucks the } \\
\text { toothbrush in and clamps her teeth on it." }\end{array}$ \\
\hline 2.5 Dysphagia & $\begin{array}{l}\text { Existing eating, drinking and } \\
\text { swallowing problems affect oral } \\
\text { care (e.g. aspirating toothpaste) }\end{array}$ & 0 & 0.0 & 4 & 2.2 & $\begin{array}{l}\text { "She swallows the water into her lungs because of } \\
\text { dysphagia" }\end{array}$ \\
\hline $\begin{array}{l}\text { 3. Organising theme: } \\
\text { Behavioural Factors }\end{array}$ & $\begin{array}{l}\text { The facilitator or barrier relates } \\
\text { to behavioural factors }\end{array}$ & 20 & 5.4 & 82 & 45.6 & \\
\hline $\begin{array}{l}\text { 3.1 Obstructive or cooperative } \\
\text { behaviour }\end{array}$ & $\begin{array}{l}\text { Behaviour which facilitates oral } \\
\text { care and tooth-brushing or } \\
\text { obstructs it from happening }\end{array}$ & 20 & 5.4 & 75 & 41.7 & $\begin{array}{l}\text { "Sarah does not want to cooperate, will not open } \\
\text { mouth. Thrashing around." } \\
\text { "He closes his mouth and eats the paste." } \\
\text { "Aidan rarely allows staff in room. He will not } \\
\text { allow any staff assistance with his personal care." } \\
\text { "He refuses to clean teeth or use mouth-wash." } \\
\text { "He brushes own teeth but sometimes I (Mum) } \\
\text { give them a clean as well. He's very cooperative." }\end{array}$ \\
\hline 3.2 Challenging Behaviour & $\begin{array}{l}\text { Behaviours that carers find } \\
\text { challenging which impede daily } \\
\text { oral care (e.g. aggressive, self- } \\
\text { injurious \& social inappropriate } \\
\text { behaviours) }\end{array}$ & 0 & 0.0 & 13 & 7.2 & $\begin{array}{l}\text { "He clamps his mouth shut and pulls his head } \\
\text { away. He will become aggressive and try and } \\
\text { head-butt, bite, kick you." } \\
\text { "He bites, pushes, scratches, blows bubbles, gets } \\
\text { upset, screams. He spits out mouthwash and can } \\
\text { become self-abusive." }\end{array}$ \\
\hline
\end{tabular}




\begin{tabular}{|c|c|c|c|c|c|c|}
\hline $\begin{array}{l}\text { 4. Organising theme: } \\
\text { Affective Factors }\end{array}$ & $\begin{array}{l}\text { The facilitator or barrier relates } \\
\text { to affective factors \& mood }\end{array}$ & 9 & 2.5 & 42 & 23.3 & \\
\hline 4.1 Mood \& Motivation & $\begin{array}{l}\text { Ability to engage in oral care } \\
\text { and brushing depends on } \\
\text { mood and motivation }\end{array}$ & 3 & 0.8 & 16 & 8.9 & $\begin{array}{l}\text { "Dependent on his mood. He will not co-operate } \\
\& \text { may bite if he has had bad day or bad sleep" } \\
\text { "He does his teeth when he thinks about it. But } \\
\text { sometimes he says he feels tired and he's difficult } \\
\text { to motivate." }\end{array}$ \\
\hline 4.2 Fear \& Distress & $\begin{array}{l}\text { Person is afraid of or anxious } \\
\text { about brushing/daily care }\end{array}$ & 0 & 0.0 & 5 & 2.8 & $\begin{array}{l}\text { He closes his mouth because he's scared of the } \\
\text { toothbrush. It takes a lot of time. } \\
\text { If he's anxious we need to wait until Larry calms } \\
\text { down before we try to brush his teeth. }\end{array}$ \\
\hline $\begin{array}{l}\text { 4.3 Like/Dislike oral care \& } \\
\text { toothbrushing }\end{array}$ & $\begin{array}{l}\text { Person likes/dislikes } \\
\text { brushing/daily care }\end{array}$ & 6 & 1.6 & 22 & 12.2 & $\begin{array}{l}\text { "He constantly moves his head from side to side, } \\
\text { he really doesn't like having it done." } \\
\text { "Staff clean her teeth for her. She likes having } \\
\text { teeth cleaned." }\end{array}$ \\
\hline $\begin{array}{l}\text { 5. Organising theme: } \\
\text { Lifestyle factors }\end{array}$ & $\begin{array}{l}\text { The facilitator or barrier relates } \\
\text { to lifestyle factors }\end{array}$ & 0 & 0.0 & 6 & 3.3 & \\
\hline 5.1 Smoking & $\begin{array}{l}\text { Smoking stains teeth or affects } \\
\text { oral health }\end{array}$ & 0 & 0.0 & 3 & 1.7 & $\begin{array}{l}\text { Needs his teeth polishing a lot because he } \\
\text { smokes. }\end{array}$ \\
\hline 5.2 Sweet food & $\begin{array}{l}\text { High intake of sugary foods } \\
\text { makes oral care more crucial }\end{array}$ & 0 & 0.0 & 2 & 1.1 & $\begin{array}{l}\text { "Very poor diet. Refuses fruit and vegetables. } \\
\text { James has a very sweet tooth" }\end{array}$ \\
\hline 5.3 Medication use & $\begin{array}{l}\text { Medication affects oral status and } \\
\text { teeth }\end{array}$ & 0 & 0.0 & 1 & 0.6 & $\begin{array}{l}\text { "Sometimes Jean bites the brush. She has } \\
\text { extensive staining from drug history" }\end{array}$ \\
\hline
\end{tabular}

a The percentages in the tables and figures indicate the proportion each help or hindrance represents of the total responses for the facilitators ( $\mathrm{N}=367)$ and hindrances $(\mathrm{N}=180)$.

${ }^{\mathrm{b}}$ All names have been changed to preserve participant anonymity 
Table 4: The organising and basic themes for Global Theme 2 - Social and environmental Influences on Daily Oral Care, the frequency with which the were reported and illustrative quotations

\begin{tabular}{|c|c|c|c|c|c|c|}
\hline \multirow[t]{2}{*}{$\begin{array}{l}\text { Global Theme } 2 \text { - Social and } \\
\text { environmental influences on } \\
\text { daily oral care }\end{array}$} & \multirow[t]{2}{*}{$\begin{array}{c}\text { Definition of Organising and } \\
\text { Basic Themes }\end{array}$} & \multicolumn{2}{|c|}{$\begin{array}{l}\text { Facilitates } \\
\text { daily oral } \\
\text { care } \\
(\mathrm{N}=367)\end{array}$} & \multicolumn{2}{|c|}{$\begin{array}{l}\text { Hinders } \\
\text { daily oral } \\
\text { care } \\
(\mathrm{N}=180)\end{array}$} & \multirow[t]{2}{*}{ Illustrative Quotations } \\
\hline & & $\mathbf{N}$ & $\%$ & $\mathbf{N}$ & $\%$ & \\
\hline $\begin{array}{l}\text { 1. Organising theme: } \\
\text { Caregiver support }\end{array}$ & $\begin{array}{l}\text { The facilitator or barrier relates } \\
\text { to caregiver support }\end{array}$ & 138 & $37.6^{\mathrm{a}}$ & 16 & 8.9 & \\
\hline $\begin{array}{l}1.1 \text { Interpersonal and } \\
\text { observational support } \\
\text { strategies }\end{array}$ & $\begin{array}{l}\text { Use of support strategies such as } \\
\text { prompting and reminding, } \\
\text { reassurance and encouragement, } \\
\text { watching and monitoring, } \\
\text { persuasion, coaxing, rewards and } \\
\text { distraction }\end{array}$ & 80 & 21.8 & 0 & 0.0 & $\begin{array}{l}\text { "Staff distract Gina" with stories. It takes constant } \\
\text { coaching and reassurance to get her to open her } \\
\text { mouth. Sometimes they lie her down on the bed" } \\
\text { "The carers do not draw any attention to brushing } \\
\text { her teeth. They speak less and make sure there } \\
\text { is, no eye contact." } \\
\text { "The staff nag him, 'You can't go out like that, } \\
\text { people won't talk to you with bad breath, look in } \\
\text { the mirror'. They remind him to clean his teeth } \\
\text { and use verbal persuasion, 'bribery and } \\
\text { corruption' (laughs) if he has not cleaned them" }\end{array}$ \\
\hline 1.2 Direct support & $\begin{array}{l}\text { One or more caregivers provide } \\
\text { direct support carrying out some } \\
\text { or all of the cleaning of teeth and } \\
\text { gums, help with part of the oral } \\
\text { care routine, or provide additional } \\
\text { cleaning. }\end{array}$ & 59 & 16.1 & 0 & 0.0 & $\begin{array}{l}\text { "His mother puts the toothpaste on the brush and } \\
\text { leaves it on the sink. He brushes his teeth himself } \\
\text { but needs help with his back teeth as he wouldn't } \\
\text { do it properly - "he's not good at things like that" } \\
\text { and needs reminding" } \\
\text { "It helps if there are two people; one restrains } \\
\text { arms. They try daily, use soft toothbrushes and } \\
\text { coax" }\end{array}$ \\
\hline 1.3 Time available & $\begin{array}{l}\text { The time available, patience and } \\
\text { perseverance of caregivers }\end{array}$ & 5 & 1.4 & 2 & 1.1 & $\begin{array}{l}\text { "He won't allow staff in room. Staff have to wait for } \\
\text { him to be ready - this may take an hour." }\end{array}$ \\
\hline $\begin{array}{l}\text { 1.4 Caregiver training and } \\
\text { advice }\end{array}$ & $\begin{array}{l}\text { Availability of training and advice } \\
\text { for caregivers }\end{array}$ & 2 & 0.5 & 3 & 1.7 & $\begin{array}{l}\text { "His mother tries to clean his teeth but he } \\
\text { heaves/gags a lot because of his nerves. She } \\
\text { has not had any advice on how to help him clean } \\
\text { his teeth but would like some." }\end{array}$ \\
\hline
\end{tabular}




\begin{tabular}{|c|c|c|c|c|c|c|}
\hline 1.5 Familiarity of caregiver & $\begin{array}{l}\text { The caregiver is known/not known } \\
\text { to the person with ID and/or } \\
\text { liked/disliked by the person with } \\
\text { ID }\end{array}$ & 3 & 0.8 & 4 & 2.2 & $\begin{array}{l}\text { "Kumar brushes his own teeth with supervision. } \\
\text { He has to be supervised by staff he is familiar with } \\
\text { and likes it. He will not do anything for certain } \\
\text { members of staff who he does not know very well } \\
\text { or dislikes." }\end{array}$ \\
\hline $\begin{array}{l}1.6 \text { Caregiver concerns and } \\
\text { beliefs }\end{array}$ & $\begin{array}{l}\text { Caregiver concerns, beliefs and } \\
\text { prior experiences which help or } \\
\text { hinder daily oral care. }\end{array}$ & 0 & 0.0 & 9 & 5.0 & $\begin{array}{l}\text { "Georgina has sore and bleeding gums and the } \\
\text { carer was worried about hurting her when } \\
\text { brushing her teeth. However, she recently had } \\
\text { advice from the dentist that a good scrub will not } \\
\text { hurt." } \\
\text { "Petra will not let her sister get near her. She gets } \\
\text { hysterical. She does not get aggressive but her } \\
\text { sister worries she might do. So her sister stops } \\
\text { trying to help Petra thinking, "She's going to have } \\
\text { a heart attack"." } \\
\text { "Tim is bigger than his mother and stronger. She } \\
\text { used to clean his teeth when he was young but } \\
\text { once he pushed her, she fell and hurt her back." }\end{array}$ \\
\hline $\begin{array}{l}\text { 2. Organising theme: } \\
\text { Equipment \& environmental } \\
\text { adaptations }\end{array}$ & $\begin{array}{l}\text { The facilitator or barrier relates } \\
\text { to equipment \& environmental } \\
\text { adaptations }\end{array}$ & 103 & 28.1 & 9 & 5.0 & \\
\hline 2.1 Toothbrush & $\begin{array}{l}\text { Specific type of toothbrush (e.g. } \\
\text { electric/manual), maintenance of } \\
\text { toothbrush helps or hinders daily } \\
\text { oral care. }\end{array}$ & 68 & 18.5 & 8 & 4.4 & $\begin{array}{l}\text { "Paul owns a very old toothbrush given to him by } \\
\text { his mum" } \\
\text { "Elena doesn't like electric toothbrushes because } \\
\text { of the noise and her sight problems make it more } \\
\text { difficult" }\end{array}$ \\
\hline 2.2 Mouth wash & $\begin{array}{l}\text { Use of oral spray, mouth wash, } \\
\text { breath spray, denture cleaners } \\
\text { and disclosure tablets }\end{array}$ & 40 & 10.9 & 8 & 4.4 & $\begin{array}{l}\text { "Claire cleans her dentures with Steradent } \\
\text { (denture cleaner) daily. She usually remembers } \\
\text { herself with occasional prompting from staff." } \\
\text { "Bob has no teeth but swills his mouth out } \\
\text { independently. He prompts himself." }\end{array}$ \\
\hline 2.3 Toothpaste & $\begin{array}{l}\text { Specific type of toothpaste, } \\
\text { including fluoride drops }\end{array}$ & 14 & 3.8 & 0 & 0.0 & "She uses strawberry toothpaste" \\
\hline 2.4 Dental suction tool & Dental suction tool is used & 2 & 0.5 & 2 & 1.1 & $\begin{array}{l}\text { "His mother has managed to acquire a dental } \\
\text { suction tool to help suck out toothpaste after }\end{array}$ \\
\hline
\end{tabular}




\begin{tabular}{|c|c|c|c|c|c|c|}
\hline & & & & & & $\begin{array}{l}\text { cleaning as he can't spit out." } \\
\text { "He has dysphagia and gets a build-up of saliva. } \\
\text { Staff have been shown how to use a 'sucker' to } \\
\text { remove it by speech and language therapists." }\end{array}$ \\
\hline 2.5 Environmental adaptations & $\begin{array}{l}\text { Adaptations are made to the } \\
\text { environment (e.g. the bathroom) }\end{array}$ & 1 & 0.3 & 0 & 0.0 & $\begin{array}{l}\text { "Everything in the bathroom was at a level that } \\
\text { she could get to because she is a wheelchair } \\
\text { user." }\end{array}$ \\
\hline $\begin{array}{l}\text { 3. Organising theme: } \\
\text { Individualised oral care } \\
\text { routine }\end{array}$ & $\begin{array}{l}\text { The facilitator or barrier relates } \\
\text { to the individualised oral care } \\
\text { routine implemented }\end{array}$ & 73 & 19.9 & 5 & 2.8 & \\
\hline $\begin{array}{l}3.1 \text { Part of person's daily } \\
\text { routine }\end{array}$ & $\begin{array}{l}\text { Oral care forms/is not part of the } \\
\text { person's daily routine. }\end{array}$ & 33 & 9.0 & 5 & 2.8 & $\begin{array}{l}\text { "Toothbrushing has to be part of Karl's daily } \\
\text { routine. He will follow instructions: right, left, front, } \\
\text { back etc." }\end{array}$ \\
\hline $\begin{array}{l}\text { 3.2 Verbal and physical } \\
\text { instruction }\end{array}$ & $\begin{array}{l}\text { People receive tailored instruction } \\
\text { and help to carry out oral care and } \\
\text { brush their teeth as part of their } \\
\text { daily routine }\end{array}$ & 36 & 9.8 & 0 & 0.0 & $\begin{array}{l}\text { "He is supported hand over hand. The caregivers } \\
\text { model for him how to clean his teeth and use } \\
\text { prompts such as, "open up". He cleans his teeth } \\
\text { himself, then they clean them for him more } \\
\text { thoroughly" }\end{array}$ \\
\hline 3.3 Location & $\begin{array}{l}\text { Specified location where oral care } \\
\text { occurs helps or hinders oral care }\end{array}$ & 10 & 2.7 & 0 & 0.0 & $\begin{array}{l}\text { "He has a special comfortable chair." } \\
\text { "Some carers brush her teeth whilst she is in the } \\
\text { bath." }\end{array}$ \\
\hline 3.4 Approaching the person & $\begin{array}{l}\text { Approaching the person in a } \\
\text { particular way helps or hinders } \\
\text { oral care (e.g. from behind, } \\
\text { avoiding eye contact) }\end{array}$ & 5 & 1.4 & 0 & 0.0 & $\begin{array}{l}\text { "The carers do not draw any attention to brushing } \\
\text { her teeth. They speak less, no eye contact." } \\
\text { "Need space, sit him down and stand behind him." }\end{array}$ \\
\hline 3.5 Individualised method & $\begin{array}{l}\text { The specific way in which oral } \\
\text { care is carried out for an individual }\end{array}$ & 3 & 0.8 & 0 & 0.0 & $\begin{array}{l}\text { "They use an electric toothbrush, less pressure, } \\
\text { less hand movement." }\end{array}$ \\
\hline
\end{tabular}

${ }^{a}$ The percentages in the tables indicate the proportion each help or hindrance represents of the total responses for the facilitators ( $\left.\mathrm{N}=367\right)$ and hindrances $(\mathrm{N}=180)$.

${ }^{\mathrm{b}}$ All names have been changed to preserve participant anonymity 